\title{
Time trends in surgery for lung cancer in France from 2005 to 2012: a nationwide study
}

\author{
Marie-Catherine Morgant ${ }^{1}$, Pierre-Benoit Pagès ${ }^{1}$, Bastien Orsini ${ }^{2}$, \\ Pierre-Emmanuel Falcoz ${ }^{3}$, Pascal-Alexandre Thomas ${ }^{2}$, \\ Françoise Le Pimpec Barthes ${ }^{5}$, Marcel Dahan ${ }^{5}$ and Alain Bernard ${ }^{1}$ for the \\ Epithor project (French Society of Thoracic and Cardiovascular Surgery)
}

Affiliations: ${ }^{1} \mathrm{CHU}$ Dijon, Bocage Central Hospital, Dijon, France. ${ }^{2} \mathrm{CHU}$ Marseille, North Hospital, Marseille, France. ${ }^{3} \mathrm{CHU}$ Strasbourg, Civil Hospital, Strasbourg, France. ${ }^{4}$ Georges Pompidou European Hospital, Paris, France. ${ }^{5} \mathrm{CHU}$ Toulouse, Larrey Hospital, Toulouse, France.

Correspondence: Pierre-Benoit Pagès, Department of Thoracic Surgery, CHU Dijon Bocage Hospital, 14 rue Gaffarel, BP 7790821079 Dijon, France. E-mail: pierrebenoit.pagesdchu-dijon.fr

ABSTRACT The aim of this study was to assess the evolution of survival in patients treated surgically for non-small cell lung cancer (NSCLC) between 2005 and 2012.

From January 2005 to December 2012, 34006 patients underwent pulmonary resection for NSCLC and were included in the French national database Epithor. Patients' characteristics, procedures and survival were analysed. Survival according to the management was evaluated for each 2-year period separately: 2005-2006, 2007-2008, 2009-2010 and 2011-2012.

The proportions of early-stage cancers and adenocarcinomas increased significantly over the periods. 3-year overall survival (OS) increased significantly from $80.5 \%$ for the first period to $81.4 \%$ for the last period. For the periods 2005-2006 and 2007-2008, 3-year OS was lower after segmentectomy than after lobectomy (77 and 73\% versus 82 and 83\%, respectively). For the periods 2009-2010 and 2011-2012, 3 -year OS in the two sub-groups was similar. OS after bi-lobectomy or pneumonectomy was lower than after lobectomy for all periods analysed. Systematic nodal dissection increased OS for all periods. Chemotherapy but not radiotherapy improved OS in the first 12 postoperative months for all periods.

Changes in histological type and stage linked to advances in surgical and medical practices since 2005 led to an increase in OS in patients with surgical-stage NSCLC.

@ERSpublications

Overall survival and postoperative mortality after lung cancer surgery improve over the last decades http://ow.ly/PdwvL 


\section{Introduction}

Lung cancer is the most serious cancer worldwide, with an estimated 1.6 million new cases and 1.38 million deaths in 2008 [1]. In Europe, lung cancer is the leading cause of death by cancer with around 260000 deaths in 2011 [2]. In France, the incidence and mortality rates were respectively 51.7 and 37.0 per 100000 person-years in men and 18.6 and 12.9 in women, and around 30000 people died from lung cancer in 2012 [3]. The incidence in men started to decrease in 2005, while it increased significantly by approximately 5.3\% per year between 1980 and 2005 in women [3]. Similar trends for women were also reported by the American College of Chest Physicians in the USA [4]. Many publications have reported that the most effective treatment to improve survival was pulmonary resection for localised non-small cell lung cancer (NSCLC) [5]. In 2009, a "cancer plan" that included new measures to improve cancer care was imposed in French university hospitals. These measures concerned cancer research, screening, and the medical and surgical management of NSCLC patients [6]. Few studies have used national databases to analyse the evolution of practices over a defined period [7, 8], and few studies based on reports from institutions or the literature have been published [9-11]. It is difficult to interpret the findings because the data lack uniformity or come from single and/or specialised centres. The aim of this study, based on the analysis of data from the French national database Epithor from 2005 to 2012, was to assess how the measures of the cancer plan had influenced overall survival and mortality in patients undergoing lung cancer resection over this period.

\section{Materials and methods \\ Data collection}

Epithor is a government-recognised clinical database, financially supported by the National Cancer Institute (Institut National du Cancer) for data-quality monitoring. Epithor is accredited by the French Health Authorities (Haute Autorité de Santé), a governmental agency dedicated to improving the quality of patient care and to guaranteeing equality within the health care system, as a methodologically appropriate tool to assess professional surgical practices. Participating in Epithor is now a requirement for medical accreditation and thoracic surgery unit certification in France [12]. Each medical record contains 50 variables, of which 14 are required to open and two to close the file. Variables are collected on a data form that includes information about every patient's personal characteristics, medical history, surgical procedures, cancer staging and outcomes [13].

The accuracy of data collection is checked in regular external onsite audits initiated in 2010. Data are sent via the internet to the national database; surgeons and patients are anonymous. Surgeons can check the quality of the way they enter the data by comparing their data with national data through a quality score ranging from 0 to $100 \%$. Moreover, participants have to check the quality of the local database for missing values by comparing its completeness with that of the national database. This comparison is expressed through a quality score ranging from 0 to $100 \%$. A score exceeding $80 \%$ is mandatory to have the local data incorporated in the national database. The accuracy of data collection is checked in regular external onsite audits initiated in 2010 [12]. Every surgeon receives a personal quality score, thus inciting them to update their data. This induces a virtuous circle. Almost all of the teams that participate in Epithor have a score above $80 \%$ for data entry. Furthermore, to benefit from the accreditation, it is necessary to have a score above $80 \%$.

The Institutional Review Board of the French Society of Thoracic and Cardiovascular Surgery approved the electronic prospective database used for this study and the study itself. Patients' consent was obtained, and patients were aware that the data collected would be used for clinical research purposes. The Institutional Review Board of the French Society of Thoracic and Cardiovascular Surgery certifies that this study respects the current regulations that govern clinical research in France, referenced as: "CERC-SFCTCV-2015-1-29-151-31-MOMa”.

\section{Study population}

From January 2005 to December 2012, 34006 patients underwent pulmonary resection for NSCLC in 103 centres in France. The baseline demographic and clinical characteristics included age, sex, American Society of Anesthesiologists (ASA) score, World Health Organization performance status, body mass index (BMI), the forced expiratory volume as a percentage and the dyspnoea score according to the Medical Research Council. The number of comorbid diseases per patient was considered a categorical variable because recent data from Epithor consistently suggested that this variable was superior to individual comorbidities in a predictive model for operative mortality [14]. Surgery-related variables included the surgical approach (thoracotomy, video assisted thoracic surgery (VATS)), the type of resection (wedge resection, segmentectomy, lobectomy, bi-lobectomy and pneumonectomy), bronchoplasty and the extent of the pulmonary resection (to the chest wall, the left atrium, the carina, the diaphragm, and the superior vena cava). Systematic nodal dissection included node sampling or radical lymphadenectomy. Surgical resection margins were classified as complete (R0) or microscopically (R1) or macroscopically (R2) 
invaded. Primary NSCLC were postoperatively classified as stage IA, IB, IIA, IIB, IIIA, IIIB or IV in accordance with the International Association for the Study of Lung Cancer Lung cancer project [15]. The histological findings were reported. Data concerning pre- and postoperative management (neo-adjuvant chemotherapy and radiotherapy, adjuvant chemotherapy and radiotherapy) were also collected.

\section{Outcome measurements}

Postoperative mortality was defined as any patient who died within the first 30 days after the operation and those who died later during the same hospitalisation. Other data analysed were prolonged air leak (exceeding 7 days), atelectasis (obstruction of a lobe or lung, requiring one or more postoperative fibroaspirations), pneumonia, bronchopleural fistula (BPF), empyema, and arrhythmia.

Overall survival (OS) was defined as the time from the date of surgery plus 30 days (to exclude in-hospital mortality) until death from any cause or the last consultation. The relationship between the surgical procedure and the different outcomes was evaluated separately for each 2-year period and longitudinal trends were analysed (2005-2006, 2007-2008, 2009-2010 and 2011-2012).

\section{Missing data}

We assumed that missing data were missing at random for ASA scores $(n=340 ; 1 \%)$, stage $(n=3682 ; 10 \%)$ and histology $(\mathrm{n}=2323 ; 7 \%)$. That is to say, the fact that the data were missing was not related to the true (unobserved) values of the missing data. We applied a multiple imputation framework to compensate for missing prognostic data such as ASA scores, stage and histology [16].

\section{Statistical analysis}

Means were compared using a parametric test (ANOVA), and Chi-squared tests were used for qualitative variables. We used multivariable logistic regression to examine the relationship between the surgical procedure and postoperative mortality during the study period after adjusting for patients' characteristics. For each 2-year period, we fitted a separate model against the surgical procedure. The period variable was used for this model. The discriminative ability of the model was expressed by the area under the receiver operating characteristic (ROC) curve. The reliability of the model was assessed with the Hosmer-Lemeshow goodness-of-fit [17].

Survival curves, constructed with the date of surgery plus 30 days as the starting point, were computed according to the Kaplan-Meier method, and differences in survival were compared with the log-rank test. We used a Cox proportional hazards regression model to adjust our survival analysis for potentially confounding factors (patients and tumours). The period variable was included in the cox model. The proportional hazard assumption was tested using the Stata command estat phtest [18]. To allow for breaches of the proportional assumption, the best-fit model was extended by allowing for time-varying covariates for those variables that were in breach the proportional hazard assumption. Multivariable parametric survival analysis was used to calculate hazard ratios and 95\% CI. Stata, version 13.0 (StataCorp, College Station, TX) was used for the statistical analyses.

\section{Results}

Patients' characteristics

Patients' characteristics are reported in table 1. Over the study period, the proportion of women, of patients older than 75 years at the time of surgery and of patients with an ASA score $\geqslant 3$ increased from 24.1 to $30.2 \%$, from 13.5 to $16 \%$ and from 41.2 to $46.4 \%$, respectively (table 1 ).

\section{Management}

Between 2005 and 2012, the use of pneumonectomy decreased significantly from 15.7 to $10.5 \%\left(\mathrm{p}<10^{-4}\right)$, while that of VATS-lobectomy increased eight-fold $(1.27$ to $10.7 \%)\left(\mathrm{p}<10^{-4}\right)$. The use of systematic nodal dissection increased significantly from 79.5 to $86.6 \%,\left(\mathrm{p}<10^{-4}\right)$, while that of bronchoplasty decreased from 2.7 to $2 \%(\mathrm{p}=0.002)$ (table 1$)$. The use of neoadjuvant chemotherapy or radiotherapy was almost halved from 15.3 to $8.6 \%$ and from 2.3 to $1.1 \%\left(\mathrm{p}<10^{-4}\right)$, respectively, and the use of adjuvant chemo- and radiotherapy also decreased from 20.5 to $15.3 \%$ and from 8.1 to $4.2 \%\left(\mathrm{p}<10^{-4}\right)$ (table 1$)$, respectively.

\section{Histology}

Between 2005 and 2012, the proportion of adenocarcinomas and Stage IA and II cancers increased significantly from 44 to $52.4 \%\left(\mathrm{p}<10^{-4}\right)$, from 17.3 to $25.6 \%$ and from 14.4 to $15.6 \%\left(\mathrm{p}<10^{-4}\right)$, respectively (table 1$)$.

\section{Perioperative complications}

Atelectasis and BPF rates decreased significantly during the four periods, from 7 to $5.8 \%$ ( $\mathrm{p}=0.014$ ) and from 1.36 to $0.55 \%\left(\mathrm{p}<10^{-4}\right)$, respectively, while pneumonia rates and arrhythmia rates increased 
TABLE 1 Patients' characteristics during the study period

\begin{tabular}{|c|c|c|c|c|c|}
\hline & $2005-2006$ & 2007-2008 & $2009-2010$ & 2011-2012 & p-value \\
\hline \multicolumn{6}{|l|}{ Demographics } \\
\hline Patients $\mathrm{n}$ & 6305 & 8091 & 9811 & 9799 & \\
\hline Women & $1520(24.1)$ & 2076 (25.7) & $2688(27.4)$ & $2960(30.2)$ & $<10^{-4}$ \\
\hline Age $\geqslant 75$ years & $853(13.5)$ & $1159(14.3)$ & $1463(14.9)$ & $1568(16)$ & $<10^{-4}$ \\
\hline \multicolumn{6}{|l|}{ Comorbidities per patient $\mathrm{n}$} \\
\hline 0 & $718(11.4)$ & $874(10.8)$ & $1038(10.6)$ & $908(9.2)$ & $<10^{-4}$ \\
\hline 1 & $1387(22)$ & $1663(20.5)$ & $1869(19)$ & $1886(19.2)$ & \\
\hline 2 & $1598(25.3)$ & $1957(24.2)$ & $2381(24.3)$ & $2459(25.1)$ & \\
\hline 3 & 2052 (32.5) & 2709 (33.5) & 3481 (35.5) & 3625 (37) & \\
\hline 4 & 550 (8.7) & $888(11)$ & $1042(10.6)$ & $931(9.4)$ & \\
\hline Surgical management & & & & & $<10^{-4}$ \\
\hline Wedge & $673(10.7)$ & $870(10.7)$ & $963(9.9)$ & 973 (9.9) & \\
\hline Segmentectomy & $163(2.6)$ & $235(2.9)$ & $429(4.4)$ & $535(5.4)$ & \\
\hline Lobectomy & $4169(66.1)$ & $5390(66.6)$ & $6688(68.2)$ & $6805(69.4)$ & \\
\hline Bi-lobectomy & $309(4.9)$ & $395(4.9)$ & $471(4.8)$ & $460(4.7)$ & \\
\hline Pneumonectomy & $991(15.7)$ & $1201(14.8)$ & $1260(12.8)$ & $1026(10.5)$ & \\
\hline Systematic nodal dissection & $5014(79.5)$ & $6724(83.1)$ & $8441(86)$ & $8489(86.6)$ & $<10^{-4}$ \\
\hline VATS lobectomy & $53(1.2)$ & $82(1.5)$ & $239(3.5)$ & $730(10.7)$ & $<10^{-4}$ \\
\hline Extended resection & 499(8) & $627(7.8)$ & $739(7.5)$ & 713(7.3) & 0.45 \\
\hline Bronchoplasty & $173(2.7)$ & $168(2)$ & $237(2.4)$ & $206(2)$ & 0.02 \\
\hline \multicolumn{6}{|l|}{ Perioperative management } \\
\hline \multicolumn{6}{|l|}{ Neoadjuvant } \\
\hline Chemotherapy & 968 (15.3) & 880 (10.9) & 1009 (10.3) & $843(8.6)$ & $<10^{-4}$ \\
\hline Radiotherapy & $149(2.3)$ & $118(1.4)$ & $133(1.3)$ & $109(1.1)$ & $<10^{-4}$ \\
\hline \multicolumn{6}{|l|}{ Adjuvant } \\
\hline Chemotherapy & $1296(20.5)$ & $1485(18.3)$ & $1421(14.5)$ & $1501(15.3)$ & $<10^{-4}$ \\
\hline Radiotherapy & $509(8.1)$ & $528(6.5)$ & $434(4.4)$ & $413(4.2)$ & $<10^{-4}$ \\
\hline \multicolumn{6}{|l|}{ Histological type } \\
\hline Squamous cells & 1894 (30) & $2249(27.8)$ & $2691(27.4)$ & $2531(25.8)$ & $<10^{-4}$ \\
\hline Adenocarcinoma & 2778 (44) & $3801(47)$ & $4977(50.7)$ & $5133(52.4)$ & \\
\hline Carcinoid & $193(3)$ & $314(3.9)$ & 377 (3.8) & $427(4.3)$ & \\
\hline Other & $383(6)$ & $542(6.7)$ & $558(5.7)$ & $411(4.2)$ & \\
\hline Small cell lung cancer & $70(1.1)$ & $78(0.9)$ & $107(1.1)$ & $81(0.8)$ & \\
\hline \multicolumn{6}{|l|}{ Tumour classification } \\
\hline IA & 1094 (17) & $1669(21)$ & $2285(23)$ & $2513(26)$ & $<10^{-4}$ \\
\hline IB & $1358(21.5)$ & $1745(21.5)$ & 2015 (20.5) & 1954 (20) & \\
\hline$\| A$ or $B$ & $909(14)$ & $1124(14)$ & $1468(15)$ & $1532(16)$ & \\
\hline IIIA & 943 (15) & $1192(15)$ & $1481(15)$ & $1382(14)$ & \\
\hline IIIB & 409 (6.5) & $515(6)$ & $562(6)$ & $427(4)$ & \\
\hline IV & $339(5)$ & $449(5.5)$ & $475(5)$ & $377(4)$ & \\
\hline
\end{tabular}

Data are presented as $\mathrm{n}(\%)$, unless otherwise stated. VATS: video assisted thoracic surgery.

gradually from 5 to $7.7 \%\left(\mathrm{p}<10^{-4}\right)$ and from 4.5 to $5.3 \%\left(\mathrm{p}<10^{-4}\right)$, respectively (table 2$)$. There was no significant difference between the time periods concerning prolonged air leak and empyema.

\section{Postoperative mortality}

In-hospital mortality gradually declined between 2005 and 2012 from 3.5 to $2.4 \%\left(\mathrm{p}<10^{-4}\right)$ (table 2). Adjusted risks for postoperative mortality are reported in table 3. The area under the ROC curve was 0.77 (95\% CI 0.76-0.78) and the result of the Hosmer-Lemeshow goodness-of-fit test was not significant $(\mathrm{p}=0.48)$, confirming that the model used for adjustment was satisfactory. Pneumonectomy was a major risk factor for perioperative death whatever the period, with a very high adjusted odds ratio (OR) ranging from 8.2 (95\% CI 3.54-19.2) for the first period to 4.46 (95\% CI 2.2-9.03) for the last one. Bronchoplasty and bi-lobectomy were also identified as risk factors for in-hospital mortality during the four periods; adjusted OR were 2.9 (95\% CI 1.5-5.6) and 3.46 (95\% CI 2.20-9.03), respectively.

\section{Survival}

Over the four periods, 3-year OS increased from 80.5\% (95\% CI 78.7-82.1) to 81.8\% (95\% CI 76.8-85.9). For the periods 2005-2006 and 2007-2008, 3-year OS in patients who underwent segmentectomy was $77 \%$ 


\begin{tabular}{|c|c|c|c|c|c|}
\hline & $2005-2006$ & $2007-2008$ & 2009-2010 & 2011-2012 & p-value \\
\hline Patients n & 6305 & 8091 & 9811 & 9799 & \\
\hline \multicolumn{6}{|l|}{ Postoperative complications } \\
\hline Atelectasis & 445 (7.0) & $534(6.6)$ & $612(6.2)$ & 572 (5.8) & 0.014 \\
\hline Air leak $>7$ days & $428(6.8)$ & $512(6.3)$ & $624(6.3)$ & $696(7.1)$ & 0.106 \\
\hline Pneumonia & $317(5)$ & 445 (5.5) & $652(6.6)$ & $753(7.7)$ & $<10^{-4}$ \\
\hline Bronchopleural fistula & $86(1.36)$ & 71 (0.88) & $67(0.68)$ & $55(0.55)$ & $<10^{-4}$ \\
\hline Empyema & $34(0.5)$ & $57(0.7)$ & $56(0.6)$ & $59(0.6)$ & 0.578 \\
\hline Arrhythmia & $283(4.5)$ & $378(4.7)$ & $574(5.8)$ & 523 (5.3) & $<10^{-4}$ \\
\hline Postoperative mortality & $221(3.5)$ & $272(3.4)$ & $281(2.9)$ & $236(2.4)$ & $<10^{-4}$ \\
\hline
\end{tabular}

(95\% CI 65-85), and 73\% (95\% CI 62-82) (figure 1a and b), respectively. In contrast, 3-year OS for patients who underwent lobectomy was $82 \%$ (95\% CI $80-84 \%$ ) and $83 \%$ (95\% CI $81-85 \%)$, respectively. For the periods 2009-2010 and 2011-2012, OS in patients who underwent segmentectomy was similar to that in patients who underwent lobectomy (figures $1 \mathrm{c}$ and $\mathrm{d}$ ). Whatever the period, OS in patients who underwent bi-lobectomy or pneumonectomy was still lower than that in patients who underwent lobectomy (figure 1).

The hazard ratios (HR) for procedures and adjuvant chemotherapy were not proportional because the proportional assumption test was significant $\left(p<10^{-4}\right)$. We split the time scale at 12 months for each period and estimated HR for the first 12 months and after 12 months (table 4). For the first 12 months, mortality was higher following lobectomy, bi-lobectomy and pneumonectomy than following segmentectomy, whatever the period analysed. After 12 months, the adjusted HRs were not significant for the four types of pulmonary resection. Systematic nodal dissection significantly decreased the mortality rate with an adjusted HR of $0.52(0.4-0.7), 0.47(0.35-0.63), 0.43(0.32-0.57), 0.5(0.4-0.64)$ for the four periods, respectively. In contrast, extended resection significantly increased the mortality rate with adjusted HR values of 1.47 (1.17-1.85), 1.4 (1.05-1.67), 1.2 (0.96-1.5), 1.43 (1.24-1.65) for the four periods, respectively. Concerning perioperative management, only adjuvant chemotherapy significantly decreased

TABLE 3 Postoperative mortality during the study period

\begin{tabular}{|c|c|c|c|c|}
\hline & $2005-2006$ & 2007-2008 & 2009-2010 & 2011-2012 \\
\hline Patients $\mathrm{n}$ & 6305 & 8091 & 9811 & 9799 \\
\hline \multicolumn{5}{|l|}{ Type of resection } \\
\hline Wedge & 1 & 1 & 1 & 1 \\
\hline Segmentectomy & $2.02(0.62-6.51)$ & $1.97(0.82-4.74)$ & $0.49(0.19-1.23)$ & $0.90(0.33-2.45)$ \\
\hline Lobectomy & $2.73(1.20-6.23)^{\#}$ & $1.62(0.88-2.99)$ & $0.72(0.39-1.32)$ & $2.17(1.14-4.13)^{\#}$ \\
\hline Bi-lobectomy & $5.95(2.33-15.2)^{\#}$ & $5.21(2.53-10.76)^{\#}$ & $0.92(0.42-2.03)$ & $3.46(1.53-7.81)^{\#}$ \\
\hline Pneumonectomy & $8.2(3.54-19.2)^{\#}$ & $4.64(2.43-8.85)^{\#}$ & $2.35(1.24-4.45)^{\#}$ & $4.46(2.20-9.03)^{\#}$ \\
\hline \multicolumn{5}{|l|}{ Surgical approach } \\
\hline Thoracotomy & 1 & 1 & 1 & 1 \\
\hline VATS & $0.61(0.22-1.65)$ & $0.17(0.05-0.58)^{\#}$ & $0.32(0.13-0.79)^{\#}$ & $0.67(0.39-1.14)$ \\
\hline \multicolumn{5}{|l|}{ Extended resection } \\
\hline No & 1 & 1 & 1 & 1 \\
\hline Yes & $1.45(0.95-2.21)$ & $1.3(0.9-1.95)$ & $1.7(1.16-2.45)^{\#}$ & $1(0.6-1.6)$ \\
\hline \multicolumn{5}{|l|}{ Bronchoplasty } \\
\hline No & 1 & 1 & 1 & 1 \\
\hline Yes & $2.9(1.5-5.62)^{\#}$ & $2.57(1.3-5)^{\#}$ & $2.43(1.3-4.6)^{\#}$ & $2.9(1.5-5.6)^{\#}$ \\
\hline \multicolumn{5}{|c|}{ Systematic nodal dissection } \\
\hline No & 1 & 1 & 1 & 1 \\
\hline Yes & $0.76(0.5-1.2)$ & $0.63(0.4-0.97)^{\#}$ & $1.14(0.6-1.62)$ & $0.66(0.4-1.09)$ \\
\hline
\end{tabular}

Data are presented as adjusted odds ratio $(95 \% \mathrm{CI})$, unless otherwise stated. Odds ratio was adjusted for age, sex, body mass index, forced expiratory volume, American Society of Anesthesiologists score, performance status, number of comorbidities per patient, preoperative chemotherapy and preoperative radiotherapy. VATS: video assisted thoracic surgery. ${ }^{\#}$ : $p<0.05$. 

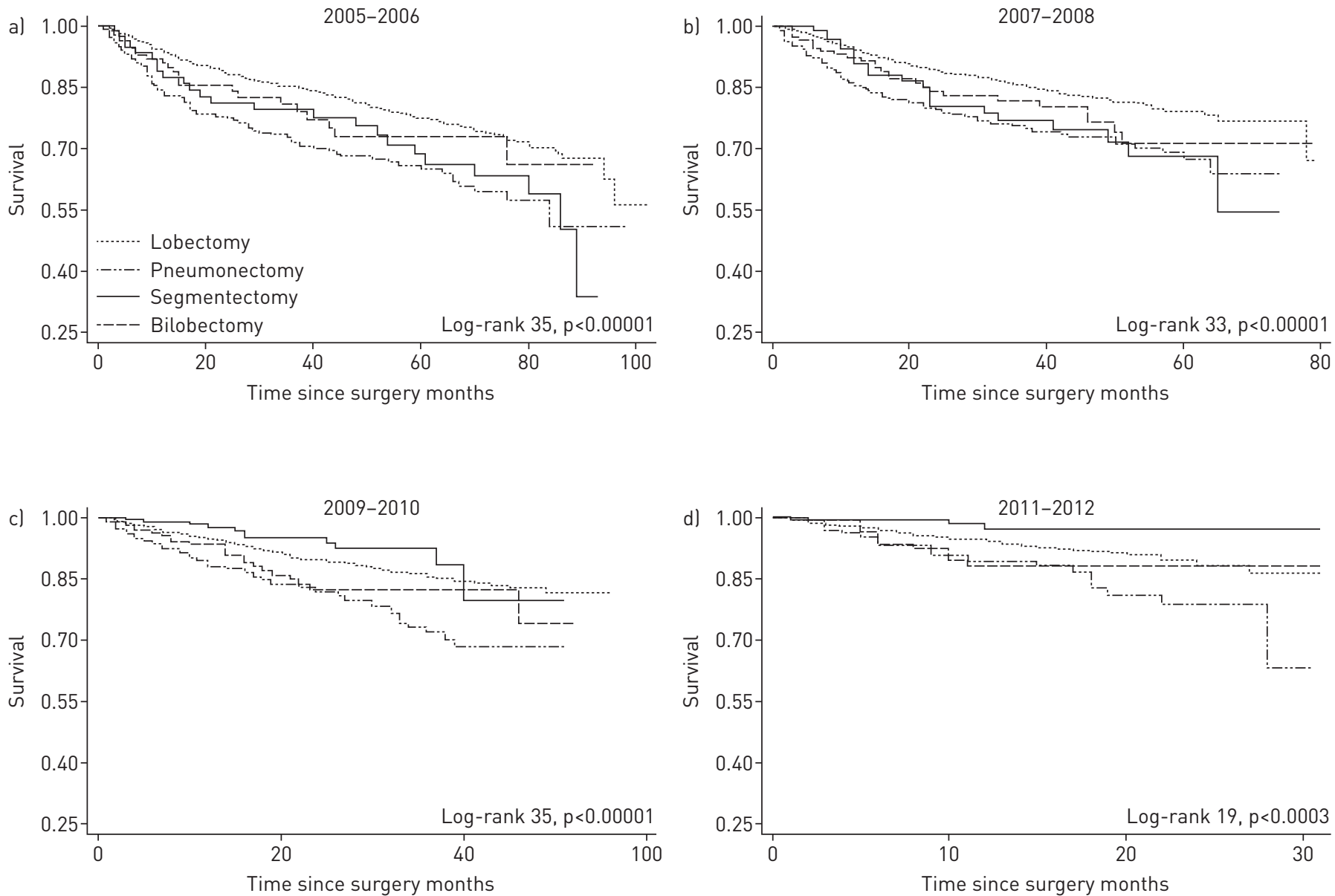

FIGURE 1 Kaplan-Meier analyses. Survival curves for patients operated on during a) 2005-2006, b) 2007-2008, c) 2009-2010, and d) 2011-2012, according to procedure.

the mortality rate during the first 12 months with adjusted HRs ranging from $0.38(0.3-0.48)$ to 0.45 (0.37-0.54) depending on the period. After 12 months, the different adjusted HR values were not significant. Neoadjuvant treatment (chemotherapy, radiotherapy) had no statistically significant impact on the mortality rate (table 4 ).

\section{Discussion}

Nowadays, surgery offers the best 5-year OS for patients presenting early-stage NSCLC [5]. However, few data are available concerning the quality of surgical management in developed countries [7, 8]. In 2009, the French Institution set up a cancer plan, whose objective was to review and to assess practices in order to improve the quality of cancer management. This study shows the positive impact of this plan, highlighted by the decrease in postoperative mortality and the increase in 3-year OS.

We analysed the French database Epithor to identify patients treated with surgery for NSCLC. We highlighted that patients became more and more fragile over the study period, with a greater proportion of older patients and of patients presenting three or more comorbidities. This increase in the age and the high number of comorbidities are important, and were identified as predictors of in-hospital mortality by BERNARD et al. [14]. As previously described by Alberg et al. [4] the proportion of women increased significantly over time from 24.1 to $30 \%$. This increase is linked to the prevalence of cigarette smoking which peaked two decades earlier in men than in women $[3,4,19]$.

\section{Surgical management}

We found an increase in the proportion of patients suffering from early-stage NSCLC. This is probably due to the better sensitivity of new-generation CT apparatus, which are able to detect NSCLC at an earlier stage [20]. Because of the increase in the proportion of early-stage cancers, we observed a decrease of the induction therapy and an increase in the use of lobar and sublobar resection and a decline in the use of 


\begin{tabular}{|c|c|c|c|c|}
\hline & $2005-2006$ & $2007-2008$ & 2009-2010 & 2011-2012 \\
\hline Segmentectomy & 1 & 1 & 1 & 1 \\
\hline \multicolumn{5}{|l|}{ Lobectomy } \\
\hline$\leqslant 12$ months & $1.7(1.06-2.7)^{*}$ & $1.6(0.97-2.6)$ & $1.4(0.86-2.3)$ & $1.7(1.06-2.67)^{*}$ \\
\hline$>12$ months & $0.86(0.56-1.31)$ & $0.8(0.53-1.22)$ & $0.71(0.47-1.09)$ & $0.85(0.57-1.26)$ \\
\hline \multicolumn{5}{|l|}{ Bi-lobectomy } \\
\hline$\leqslant 12$ months & $2.3(1.33-3.98)^{*}$ & $2.16(1.25-3.7)^{*}$ & $1.92(1.1-3.3)^{*}$ & $2.28(1.36-3.85)^{*}$ \\
\hline$>12$ months & $1.04(0.61-1.77)$ & $0.97(0.58-1.64)$ & $0.86(0.5-1.47)$ & $1.03(0.63-1.5)$ \\
\hline \multicolumn{5}{|l|}{ Pneumonectomy } \\
\hline$\leqslant 12$ months & $2.81(1.7-4.66)^{*}$ & $2.63(1.59-4.35)^{*}$ & $2.3(1.41-3.88)^{*}$ & $2.8(1.72-4.35)^{*}$ \\
\hline >12 months & $1.05(0.66-1.67)$ & $0.98(0.62-1.55)$ & $0.87(0.55-1.38)$ & $1.04(0.67-1.6)$ \\
\hline \multicolumn{5}{|l|}{ Approach } \\
\hline Thoracotomy & 1 & 1 & 1 & 1 \\
\hline VATS & $0.7(0.43-1.16)$ & $0.64(0.38-1.04)$ & $0.58(0.35-0.95)^{*}$ & $0.7(0.44-1.07)$ \\
\hline \multicolumn{5}{|l|}{ Extended resection } \\
\hline No & 1 & 1 & 1 & 1 \\
\hline Yes & $1.47(1.17-1.85)^{*}$ & $1.4(1.05-1.67)^{*}$ & $1.2(0.96-1.5)$ & $1.43(1.24-1.65)^{*}$ \\
\hline \multicolumn{5}{|l|}{ Bronchoplasty } \\
\hline No & 1 & 1 & 1 & 1 \\
\hline Yes & $1.13(0.8-1.6)$ & $1.02(0.72-1.44)$ & $0.93(0.66-1.3)$ & $1.1(0.8-1.48)$ \\
\hline \multicolumn{5}{|l|}{$\begin{array}{l}\text { Systematic nodal } \\
\text { dissection }\end{array}$} \\
\hline No & 1 & 1 & 1 & 1 \\
\hline Yes & $0.52(0.4-0.7)^{*}$ & $0.47(0.35-0.63)^{*}$ & $0.43(0.32-0.57)^{*}$ & $0.5(0.4-0.64)^{*}$ \\
\hline \multicolumn{5}{|l|}{ Neo-adjuvant } \\
\hline Chemotherapy & $1.05(0.84-1.3)$ & $0.95(0.76-1.18)$ & $0.86(0.7-1.07)$ & $1.01(0.88-1.17)$ \\
\hline Radiotherapy & $0.83(0.55-1.23)$ & $0.74(0.5-1.11)$ & $0.67(0.45-1.01)$ & $0.8(0.55-1.16)$ \\
\hline \multicolumn{5}{|l|}{ Adjuvant chemotherapy } \\
\hline$\leqslant 12$ months & $0.45(0.35-0.58)^{*}$ & $0.42(0.33-0.54)^{*}$ & $0.38(0.3-0.48)^{*}$ & $0.45(0.37-0.54)^{*}$ \\
\hline$>12$ months & $0.94(0.7-1.2)$ & $0.88(0.68-1.13)$ & $0.78(0.6-1.01)$ & $0.93(0.77-1.12)$ \\
\hline Adjuvant radiotherapy & $1.1(0.88-1.4)$ & $1(0.8-1.26)$ & $0.9(0.72-1.15)$ & $1.08(0.9-1.27)$ \\
\hline
\end{tabular}

Data are presented as adjusted hazard ratio $(95 \% \mathrm{CI})$. Hazard ratios were adjusted for age, sex, American Society of Anesthesiologists score, number of comorbidities per patient, stage, histology and surgical resection margins. VATS: video assisted thoracic surgery. ${ }^{*}: p<0.05$.

pneumonectomy. Moreover, the proportion of lobectomies performed using the VATS approach increased eight-fold. This is consistent with the American College of Chest Physicians guidelines, which advise experienced centres to use minimally-invasive approaches such as VATS rather than thoracotomy [5].

\section{Postoperative complications and mortality}

Over the study period, there was a decline in the frequency of postoperative complications such as atelectasis and fistula. In contrast, the frequency of pneumonia and arrhythmia rose. We noticed a significant decrease in postoperative mortality, which might be explained by various factors. First, the quality of postoperative management improved over time, and the incidence of BPF, which is linked to high mortality, declined [21]. This fall was linked to the decreased use of pneumonectomy over the study period. Although postoperative management improved, major pulmonary resections, such as bi-lobectomy or pneumonectomy, were still burdened by a high mortality rate, due to the gravity of the resection itself, as previously described [14]. Indeed, the effect of pneumonectomy on postoperative mortality and on overall survival was very important, as shown by the high values of the OR and the HR far from the limits of the 95\% confidence interval (tables 3 and 4). Moreover, the higher proportion of early-stage NSCLC in recent periods, and the decrease in the use of induction therapy might also explain the decrease in postoperative complications.

In contrast, VATS procedures, performed for smaller resections, decreased the risk of postoperative death by decreasing postoperative complications such as atelectasis, or pneumonia. VATS is also associated with decreased postoperative pain [22]. Surprisingly, systematic nodal dissection decreased in-hospital mortality, though the explanation for this is unknown. 


\section{Overall survival}

3-year OS increased gradually over the four periods, which is in keeping with data from other national registries: UK, Germany and Norway [7, 8, 10]. Segmentectomy, compared with other resections, seemed to be a protective factor in the first 12 months after surgery, but this effect was no longer present after 12 months. This loss of benefit in terms of survival after 12 months could be tied to a higher risk of recurrence, highlighted by an increase in mortality after 3 years. For long-term OS, lobectomy seemed to be the best procedure, whatever the period. Indeed, bi-lobectomy and pneumonectomy led to a higher death rate in the first 12 months, because of the major complications associated with these procedures. A recent study that compared lobectomy with segmentectomy for early-stage NSCLC reported similar OS for the two procedures, but the number of patients undergoing segmentectomy was smaller than in our study $[23,24]$. VATS appeared to be a protective factor although the difference was not significant for two periods (2005-2006 and 2011-2012).

In our study, only adjuvant chemotherapy given during the first 12 months after surgery seemed to be a protective factor for OS, but these effects disappeared after 12 months. Analysis of the data supporting adjuvant chemotherapy after surgery for NSCLC showed a small benefit of adjuvant chemotherapy of less than $5 \%$ at 5 years. These studies, however, had a small number of patients [25]. Moreover, we found no correlation between OS and adjuvant radiotherapy, which needs to be evaluated in particular cases, such as postoperative N2-NSCLC.

This study was not a randomised control trial (RCT), and did not allow us to draw conclusions in terms of the causality of one treatment with regard to another one. However, such studies on large databases are essential to observe the reality of lung cancer management. RCTs are essential to demonstrate the efficacy of a treatment, but they needs to be associated with real-life observational studies to confirm this efficacy and to assess complications.

The main strengths of this study are the population size with 34000 patients and the long period of analysis (8 years). In addition, because data from a national database were used, the population was homogeneous. The main bias is related to the retrospective nature, with the inevitable missing data, and the lack of information on the recurrence rate and the causes of death.

\section{Conclusion}

Analysis of data from the national Epithor database showed an evolution in the surgical management of NSCLC resulting in a steady decrease in postoperative mortality and an increase in long-term survival. These changes are probably linked to the increase in early-stage NSCLC and the reduced use of pneumonectomy.

\section{Acknowledgements}

This work was performed at the French Society of Thoracic and Cardiovascular surgery. The authors would like to thank Philip Bastable (Dijon University Hospital, Dijon, France) for revising the manuscript.

The authors would like to thank all the French thoracic surgeons who participated in Epithor and subsequently in this study in order to improve thoracic surgery quality: Michel Alauzen (Montpellier), Jean-François Andro (Quimper), Maxime Aubert (Grenoble), Jean Philippe Avaro (Marseille), Patrick Bagan (Argenteuil), Francois Bellenot (Cergy Pontoise), Vincent Blin (Vannes), Philippe Boitet (Harfleur), Laurent Bordigoni (Toulon), Jacques Borrelly (Nancy), PierreYves Brichon (Grenoble), Gilles Cardot (Boulogne sur Mer), Jean Michel Carrie (Saint Jean), François Clement (Besançon), Pierre Corbi (Poitiers), Michel Debaert (Lille), Bertrand Debrueres (Ploemeur), Jean Dubrez (Bayonne), Xavier Ducrocq (Strasbourg), Antoine Dujon (Bois Guillaume), Pascal Dumont (Tours), Philippe Fernoux (Chalon sur Saône), Marc Filaire (Clermont-Ferrand), Eric Frassinetti (Chambéry), Gil Frey (Saint Etienne), Dominique Gossot (Paris), Gilles Grosdidier (Nancy), Benoit Guibert (Lyon), Olivier Hagry (Chalon sur Saône), Sophie Jaillard (Lille), Jean-Marc Jarry (Aix en Provence), David Kaczmarek (Saint Etienne), Yves Laborde (Pau), Bernard Lenot (Saint Brieuc), Francis Levy (Bordeaux), Laurent Lombart (Béziers), Eric Marcade (Saint Grégoire), Jean Paul Marcade (La Rochelle), Jean Marzelle (Créteil), Gilbert Massard (Strasbourg), Florence Mazeres (Bayonne), Eric Mensier (Lille), David Metois (Orléans), J.L. Michaud and E. Paris (Nantes), Philippe Mondine (Brest), Michel Monteau (Reims), Jean-Michel Moreau (Nantes), Jérome Mouroux (Nice), Antoine Mugniot (Nantes), Pierre Mulsant (Lyon), Nidal Naffaa (Avignon), Gérard Pavy (Arras), Christophe Peillon (Rouen), Francois Pons (Percy), Henri Porte (Lille), Jean-Francois Regnard (Paris), Marc Riquet (Paris), Babak Sadeghi Looyeh (Morlaix), Olivier Tiffet (Saint Etienne), Bruno Tremblay (Meaux), Jean Valla (Charenton le Pont), Jean-François Velly (Pessac), Bernard Wack (Metz), Jean-Didier Wagner (Colmar), and Didier Woelffe (Valenciennes).

\section{References}

1 Jemal A, Bray F, Center MM, et al. Global cancer statistics. CA Cancer J Clin 2011; 61: 69-90.

2 Eurostat News. Causes of deaths in the EU28 in 2011. http://ec.europa.eu/eurostat/documents/2995521/6131615/ 3-25112014-BP-EN/aab2c2d3-aed9-430a-a561-e188b8ef49d8 Date last accessed: November 25, 2014.

3 Binder-Foucard F, Bossard N, Delafosse Pl. Cancer incidence and mortality in France over the 1980-2012 period: solid tumors. Rev Epidemiol Sante Publique 2014; 62: 95-108.

4 Alberg AJ, Ford JG, Samet JM, et al. Epidemiology of lung cancer: ACCP evidence-based clinical practice guidelines (2nd edition). Chest 2007; 132: Suppl. 3, 29S-55S. 
5 Howington JA, Blum MG, Chang AC, et al. Treatment of stage I and II non-small cell lung cancer: Diagnosis and management of lung cancer, 3rd ed: American College of Chest Physicians evidence-based clinical practice guidelines. Chest 2013; 143: Suppl. 5, e278S-e313S.

6 Grünfeld J-R. Recommandations pour le plan cancer, 2009-2013. [Recommendations for the cancer plan, 20092013.] www.afsos.org/documents/rapport_Grunfeld_Plan_Cancer.pdf Date last accessed December 20, 2014.

7 Damhuis RA, Schütte PR. Resection rates and postoperative mortality in 7,899 patients with lung cancer. Eur Respir J 1996; 9: 7-10.

8 Strand TE, Bartnes K, Rostad H. National trends in lung cancer surgery. Eur J CardioThorac Surg 2012; 42: $355-358$.

9 Okada M, Nishio W, Sakamoto T, et al. Evolution of surgical outcomes for nonsmall cell lung cancer: time trends in 1465 consecutive patients undergoing complete resection. Ann Thorac Surg 2004; 77: 1926-1930.

10 Powell HA, Tata LJ, Baldwin DR, et al. Early mortality after surgical resection for lung cancer: an analysis of the English National Lung cancer audit. Thorax 2013; 68: 826-834.

11 Dillman RO, McClure SE. Steadily improving survival in lung cancer. Clin Lung Cancer 2014; 15: 331-337.

12 Thomas PA, Berbis J, Falcoz PE, et al. National perioperative outcomes of pulmonary lobectomy for cancer: the influence of nutritional status. Eur J CardioThorac Surg 2014; 45: 652-659.

13 Pagès PB, Delpy JP, Falcoz PE, et al. Videothoracoscopy vs thoracotomy for the treatment of primary spontaneous pneumothorax-a propensity score analysis. Ann Thorac Surg 2015; 99: 258-264.

14 Bernard A, Rivera C, Pagès PB, et al. Risk model of in-hospital mortality after pulmonary resection for cancer: a national database of the French Society of Thoracic and Cardiovascular Surgery (Epithor). J Thorac Cardiovasc Surg 2011; 141: 449-458.

15 Goldstraw P, Crowley J, Chansky K, et al. The IASLC lung cancer staging project: proposals for the revision of the TNM stage groupings in the forthcoming (seventh) edition of the TNM classification of malignant tumours. J Thorac Oncol 2007; 2: 706-714.

16 Schafer JL. Multiple imputation: a primer. Stat Methods Med Res 1999; 8: 3-15.

17 Steyerberg EW. Applications of prediction models. Clinical Prediction Models. New York, Springer, 2009; pp. 11-31.

18 Schwender H, Hosmer DW, Lemeshow S, et al. Applied survival analysis: regression modeling of time-to-event data. Stat Pap 2012; 53: 247-248.

19 Beattie G, Bannon F, McGuigan J. Lung cancer resection rates have increased significantly in females during a 15-year period. Eur J CardioThorac Surg 2010; 38: 484-490.

20 National Lung Screening Trial Research Team,Aberle DR, Adams AM, Berg CD, et al. Reduced lung-cancer mortality with low-dose computed tomographic screening. N Engl J Med 2011; 365: 395-409.

21 Hu X, Duan L, Jiang G, et al. A clinical risk model for the evaluation of bronchopleural fistula in non-small cell lung cancer after pneumonectomy. Ann Thorac Surg 2013; 96: 419-424.

22 Paul S, Isaacs AJ, Treasure T, et al. Long term survival with thoracoscopic versus open lobectomy: propensity matched comparative analysis using SEER-Medicare database. BMJ 2014; 349: g5575.

23 Villamizar N, Swanson SJ. Lobectomy vs. segmentectomy for NSCLC (T<2 cm) Ann Cardiothorac Surg 2014; 3 : $160-166$.

24 Tsutani Y, Miyata Y, Nakayama H, et al. Oncologic outcomes of segmentectomy compared with lobectomy for clinical stage IA lung adenocarcinoma: propensity score-matched analysis in a multicenter study. $J$ Thorac Cardiovasc Surg 2013; 146: 358-364.

25 Leong D, Rai R, Nguyen B, et al. Advances in adjuvant systemic therapy for non-small-cell lung cancer. World J Clin Oncol 2014; 5: 633-645. 